AperTO - Archivio Istituzionale Open Access dell'Università di Torino

\title{
Influence of the Sonic Anemometer Temperature Calibration on Turbulent Heat-Flux Measurements
}

\section{This is the author's manuscript}

Original Citation:

Availability:

This version is available http://hdl.handle.net/2318/98174

since

Published version:

DOI:10.1007/s10546-011-9688-z

Terms of use:

Open Access

Anyone can freely access the full text of works made available as "Open Access". Works made available under a Creative Commons license can be used according to the terms and conditions of said license. Use of all other works requires consent of the right holder (author or publisher) if not exempted from copyright protection by the applicable law. 


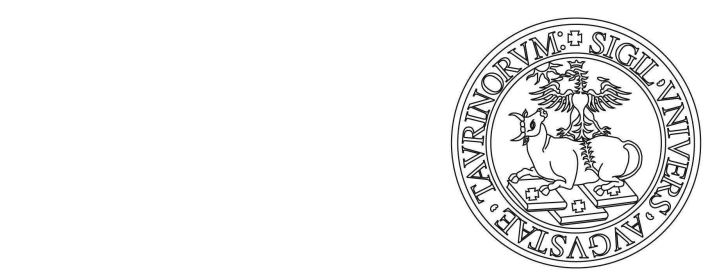

\section{UNIVERSITÀ DEGLI STUDI DI TORINO}

This is an author version of the contribution published on:

Richiardone R., Manfrin M., Ferrarese S., Francone C., Fernicola V., Gavioso R.M., Mortarini L. (2012) : Influence of the Sonic Anemometer Temperature Calibration on Turbulent Heat-Flux Measurements. Boundary-Layer Meteorology, 142, pp. 425 - 442. DOI: 10.1007/s10546-011-9688-z .

The final publication is available at Springer via

http://link.springer.com/article/10.1007/s10546-011-9688-z\#page-1 
Boundary-Layer Meteorology manuscript No.

(will be inserted by the editor)

\title{
Influence of the Sonic Anemometer Temperature Calibration on Turbulent Heat-Flux Measurements (MANUSCRIPT)
}

\author{
Renzo Richiardone · Massimiliano Manfrin \\ Silvia Ferrarese · Caterina Francone · Vito \\ Fernicola - Roberto Maria Gavioso · Luca \\ Mortarini
}

Received: date / Accepted: date

\begin{abstract}
The speed of sound in moist air is discussed and a more accurate value for the coefficient of the linear dependence of sonic temperature on specific humidity is proposed. An analysis of speed-of-sound data measured by three sonic anemometers in a climatic chamber and in the field shows that the temperature response of each instrument significantly influences not only the determination of sonic temperature, but also its fluctuations. The corresponding relative contribution to the error in the evaluation of the temperature fluctuations and the turbulent heat fluxes can be as high as $40 \%$. The calibration procedure is discussed and a method of correction is proposed.
\end{abstract}

Keywords Moist air - Speed of sound - Sonic anemometers - Turbulent heat flux measurement.

Author for correspondence : E-mail: richiardone@ph.unito.it Tel.: (+39)-011-670-7444 ; Fax: (+39)-011$658-444$

R. Richiardone $\cdot$ Massimiliano Manfrin · Silvia Ferrarese

Dipartimento di Fisica, Università di Torino, via P. Giuria 1, 10125 Torino, Italy

Caterina Francone

Dipartimento di Fisica, Università di Torino, via P. Giuria 1, 10125 Torino, Italy

Dipartimento di Ingegneria Aerospaziale, Politecnico di Torino, corso Duca degli Abruzzi 24, 10129

Torino, Italy

Vito Fernicola $\cdot$ Roberto Maria Gavioso

INRIM - Istituto Nazionale di Ricerca Metrologica, strada delle Cacce 91, 10135 Torino, Italy

Luca Mortarini

ISAC-TO Istituto di Scienze dell'Atmosfera e del Clima - Sezione di Torino, corso Fiume 4, 10133 Torino, Italy 


\section{Introduction}

Sonic anemometers are currently used to evaluate the turbulent heat flux from the sonic kinematic heat flux (or "temperature flux") $\overline{w^{\prime} T_{s}^{\prime}}$, i.e. the covariance of the vertical wind velocity $w$ and the sonic temperature

$$
T_{s} \equiv \frac{c^{2}}{\gamma_{\mathrm{d}} R_{d}}
$$

the vertical wind velocity $w$ and the speed of sound $c$ being simultaneously measured by the anemometer, and the speed of sound being then corrected for the effect of the crosswind (Kaimal and Gaynor 1991). In this equation $\gamma_{\mathrm{d}}=c_{p_{\mathrm{d}}} / c_{v_{\mathrm{d}}}$ is the ratio of the isobaric and isochoric specific heat capacities of dry air, and $R_{d}=R^{*} / M_{d}$ is the specific gas constant of dry air, where $R^{*}=8.314472(15) \mathrm{J} \mathrm{mol}^{-1} \mathrm{~K}^{-1}$ is the universal molar gas constant (Zuckerwar 2002) and $M_{d}=28.9645 \times 10^{-3} \mathrm{~kg} \mathrm{~mol}^{-1}$ is the molar mass of dry air (ISO 1975).

In moist air the speed of sound depends on the water vapour mole fraction, and at first order the dependency of the squared speed of sound on humidity may be conveniently approximated as linear. In the meteorological literature, one of the most used approximations is

$$
c_{a}^{2}=\gamma_{\mathrm{d}} R_{\mathrm{d}} T(1+\eta q),
$$

where $c_{a}$ indicates the approximated value of the speed of sound, $T$ is the absolute temperature, $q$ is the specific humidity and $\eta=0.51$ is a numerical constant (Schotanus et al. 1983; Hignett 1992; Liu et al. 2001).

From Eq. 1, Eq. 2 implies that the sonic temperature can be approximated as

$$
T_{s}=T(1+\eta q) .
$$

Strictly, the sonic kinematic heat flux $\overline{w^{\prime} T_{s}^{\prime}}$ is only a first-order approximation to the kinematic heat flux $\overline{w^{\prime} T^{\prime}}$ required to evaluate the (sensible) heat flux $\rho c_{p} \overline{w^{\prime} T^{\prime}}$ (Högstrom and Smedman 2004), because from Eq. 3 (Schotanus et al. 1983)

$$
\overline{w^{\prime} T^{\prime}} \cong \overline{w^{\prime} T_{s}^{\prime}}-\eta \bar{T} \overline{w^{\prime} q^{\prime}}
$$

Different methods have been proposed (Schotanus et al. 1983; Hignett 1992) to improve the evaluation of $\overline{w^{\prime} T^{\prime}}$ using solely sonic anemometer data, thus avoiding the need of fast response hygrometers to evaluate the last term in Eq. 4 or the need to use fragile transducers such as fine resistance wires or thermocouples to measure the temperature fluctuations directly.

Uncertainty contributions arising from the evaluation of $\overline{w^{\prime} T^{\prime}}$ from $\overline{w^{\prime} T_{s}^{\prime}}$ have received much more attention than those introduced from the imperfect or neglected anemometer calibration, in spite of the systematic nature of the latter. Calibration data are often relegated to field reports or are the subject of private communications. The problems concerning the measuring devices, the procedures adopted for data handling, and the observance of optimal measuring field conditions are often underestimated (Foken and Wichura 1996). More recently, Loescher et al. (2005) pointed out that the users of sonic anemometers should check and, if necessary, correct for possible non-linearities in the temperature response of the instrument. These 
authors compared the sonic temperature measured by different model anemometers over the temperature range $\left(0-30^{\circ} \mathrm{C}\right)$ and low humidity conditions. Measurements were made both in an acoustically isolated, thermally controlled climatic chamber and in the field. They concluded that the uncertainty contributions arising from the thermal response of the instruments may relevantly affect not only different types of anemometers but also different exemplars of the same type from the same manufacturer. In addition to some non-linearity, many anemometers showed a temperature response that significantly deviated from the expected 1:1 slope. Loescher et al. (2005) found that measurement spread in the sonic kinematic heat flux $\overline{w^{\prime} T_{s}^{\prime}}$ among different sensors due to their different temperature responses ranged between $-23.1 \%$ and $+16.1 \%$, and that spectra were also affected.

In this work we present and discuss the results of a comparison between the performance of three anemometers of the same model (Solent R2 by Gill Instruments) over a wider temperature range $\left(-20\right.$ to $\left.50^{\circ} \mathrm{C}\right)$ and various humidity conditions. In particular, the influence on the heat-flux measurement of any deviation of the temperature response from a 1:1 slope is pointed out, showing that the estimation of the heat flux is not only affected by non-linearities, but also by a linear response that may significantly differ from 1:1. Measurements were made both in an acoustically isolated, thermally and humidity controlled climatic chamber and in the field. The speed of sound in the atmospheric medium is dealt with in Sect. 2, where a modification of the coefficient in the relationship between speed of sound and specific humidity is proposed. The adopted experimental procedures and the measurements results are described in Sect. 3, and the influence of the temperature response of the anemometers on the heat-flux measurement is discussed in Sect. 4.

\section{Speed of Sound in Moist Air}

In ideal gas conditions, the squared speed of sound $c_{0}^{2}$ takes the simple form:

$$
c_{0}^{2}=\gamma_{0} R T,
$$

where $R=R^{*} / M$ is the specific gas constant, $M$ is the molar mass and $\gamma_{0}$ is the ratio of the isobaric $c_{p}$ and isochoric $c_{v}$ specific heat capacities. Basic kinetic theory considerations for rigid molecules give $\gamma_{0}=(d+2) / d$ where $d$ is the number of vibrational and rotational degrees of freedom, which may be selectively activated depending on the temperature $T$ and the acoustic frequency $f$. While a thorough discussion of acoustic propagation and the underlying physical mechanisms in a general case is outside the scope of this work and may be found elsewhere (e.g. Trusler (1991); Zuckerwar (2002)), it is worth recalling that for a real gas mixture such as moist air the speed of sound would additionally depend on the mixture composition (i.e. on the relative humidity $h$ ) and the pressure $p$ via the virial correction of the equation of state. Thus, using the notation proposed by Zuckerwar (2002), the speed of sound in moist air is more rigorously expressed as:

$$
c^{2}(T, h, p, f)=c_{0}^{2}(T, h)\left(1+K_{c}(T, h)\right)\left(1+K_{v}(T, h, p)\right)\left(1+K_{r}(T, h, p, f)\right),
$$


where the dependence upon the relevant thermodynamic variables and the acoustic frequency is made explicit. In Eq. 6 the correction factor $K_{c}(T, h)$ accounts for the dependence of the heat capacities of moist air on temperature and humidity. The heat capacities of a gas also depend on pressure, as the validity of the ideal gas law decreases as the pressure increases. This pressure dependency is incorporated in the virial correction $K_{v}(T, h, p)$, which accounts for the forces exerted between interacting molecules. Finally, the relaxation correction $K_{r}(T, h, p, f)$ accounts for the possible energy exchanges among different active degrees of freedom. Despite the inherent difficulties, the calculation of the speed of sound in moist air has been evaluated by Zuckerwar (2002) and speed-of-sound data as a function of temperature, pressure, humidity and acoustic frequency are currently available in the form of tabulations, capable of straightforward and accurate interpolation. The relative uncertainty associated with the squared speed of sound according to the model in Eq. 6 was estimated by Zuckerwar (2002) to amount to about $0.2 \%$ and is approximately constant over the whole $(T, h, p, f)$ range of interest for sonic anemometry. We remark that the corresponding contribution to the absolute uncertainty of the sonic temperature $\sigma_{T_{s}} \approx 0.6{ }^{\circ} \mathrm{C}$ is substantial and represents the ultimate limit of accuracy achievable by a calibration procedure. In the context of sonic anemometry the variables that mainly influence the speed of sound in moist air are temperature and humidity. In fact, the carrier frequency of the ultrasonic transducers used for the construction of anemometers may vary between 20 and $50 \mathrm{kHz}$. In this frequency range the corresponding relaxation correction is less than $0.1 \%$. Also, the influence of pressure is negligible (at $20^{\circ} \mathrm{C}$ in dry air, the relative change of the speed of sound between 500 $\mathrm{hPa}$ and $1,000 \mathrm{hPa}$ is about $0.01 \%$ ). Therefore, while keeping the results of a rigorous calculation with Eq. 6 as a reference, the simpler approximated expression

$$
c_{a}^{2}(T, h)=\gamma(T, h) R(h) T
$$

for the speed of sound in a binary mixture of dry air and water vapour can be used for sonic anemometry. In Eq. 7 the temperature and humidity dependencies of the heat capacity ratio $\gamma$ and the specific gas constant of the mixture

$$
R=(1+0.608 q) R_{\mathrm{d}}
$$

are kept into account. For this purpose, we list in Table 1 the temperature dependency of the specific heat capacities of dry air at atmospheric pressure and saturated water vapour together with their values predicted from ideal gas kinetic theory (with $M_{v}=$ $18.0153 \times 10^{-3} \mathrm{~kg} \mathrm{~mol}^{-1}$ from Wagner and Pruss (2002)).

Specific heat capacities of moist air can be derived from those of dry air and water vapour and therefore depend on their proportions. For the isobaric and the isochoric heat capacities of moist air Iribarne and Godson (1981) provide the estimates

$$
\begin{aligned}
& c_{p}=(1+\alpha q) c_{p_{\mathrm{d}}}, \\
& c_{v}=(1+\beta q) c_{v_{\mathrm{d}}},
\end{aligned}
$$

with $\alpha \equiv\left(c_{p_{\mathrm{v}}} / c_{p_{\mathrm{d}}}-1\right)$ and $\beta \equiv\left(c_{v_{\mathrm{v}}} / c_{v_{\mathrm{d}}}-1\right)$, where $c_{p_{\mathrm{v}}}$ and $c_{v_{\mathrm{v}}}$ are the isobaric and isochoric specific heat capacities of water vapour. If the ideal gas values are used, 
one obtains $\alpha=0.837$ and $\beta=0.929$ (Iribarne and Godson (1981) use $\alpha=0.87$ and $\beta=0.97$ ), but if the specific heat capacities in Table 1 are instead considered, temperature dependent values for $\alpha$ and $\beta$ are obtained (Table 2).

The ratio of specific heat capacities for moist air $\gamma=c_{p} / c_{v}$ can be derived from Eqs. 9 and 10, and at first order in $q$ the relationship

$$
\gamma=(1-v q) \gamma_{\mathrm{d}}
$$

is obtained, with $v=\beta-\alpha$ (Table 2). This relation agrees, within the experimental uncertainties, with the measurements of the dependence of $\gamma$ on relative humidity made by Wong and Embleton (1985a) at standard pressure and temperatures of $10^{\circ} \mathrm{C}$, $20^{\circ} \mathrm{C}$ and $25^{\circ} \mathrm{C}$ ( $v$ values at $25^{\circ} \mathrm{C}$ obtained by interpolation of the data in Table 2 ).

By substituting Eq. 11 and Eq. 8 into Eq. 7, one obtains at first order in specific humidity $q$ the expression (2) for the squared speed of sound in moist air, where $\eta=0.608-v$ slightly depends on temperature (Table 2 ). All the values listed in Table 2 are lower than the traditional value $\eta=0.51$ used in the meteorological literature. Moreover, $\eta$ is almost constant at temperatures above $10^{\circ} \mathrm{C}$, the absolute uncertainty $\sigma_{\eta}$ contributing to the uncertainty of the sonic temperature $\sigma_{T_{s}}$ as $\sigma_{T_{s}}=$ $T q \sigma_{\eta}$. In saturation conditions the value of $q$ is highest and the uncertainty $\sigma_{\eta}=$ 0.001 contributes to the uncertainty of the sonic temperature as $\sigma_{T_{s}}=0.008^{\circ} \mathrm{C}$ at $30{ }^{\circ} \mathrm{C}$ (the contribution is lower by a factor 20 at $-10{ }^{\circ} \mathrm{C}$ and amounts to $0.014{ }^{\circ} \mathrm{C}$ at $40^{\circ} \mathrm{C}$ ). Thus, from the data in Table 2 it is evident that the use of the constant value $\eta=0.502$ rather than a temperature dependent value, would not have any appreciable influence on the sonic temperature uncertainty in the temperature range from -20 to $40{ }^{\circ} \mathrm{C}$. We therefore propose to estimate the speed of sound by means of Eq. 2 and the sonic temperature by means of Eq. 3 using the three-significant digits value $\eta=$ 0.502 instead of the usual value $\eta=0.51$, though the relative overestimation caused by the latter is lower than the relative uncertainty implied in Eq. 6. A comparison between this approximated value of the speed of sound and the more rigorous model in Eq. 6 shows that the relative error of the approximation in Eq. 2 is lower than $0.1 \%$ (Table 4).

Another approximation that is often found in the meteorological literature is

$$
c_{a}^{2}=\gamma_{\mathrm{d}} R_{\mathrm{d}} T\left(1+\chi \frac{e}{p}\right),
$$

where $e$ is the partial pressure of water vapour and $\chi=0.32$. This value can be traced back to Kaimal and Businger (1963), who probably rounded the value $\chi=0.3192$ used by Barrett and Suomi (1949), who took the value from Ishii (1935).

From Eq. 1, Eq. 12 implies that the sonic temperature can be calculated as

$$
T_{s}=T\left(1+\chi \frac{e}{p}\right) .
$$

This expression is consistent with Eq. 2, with $\chi=\varepsilon \eta$, if the approximation

$$
q \approx \varepsilon \frac{e}{p}
$$


is used, where $\varepsilon=M_{\mathrm{v}} / M_{\mathrm{d}} \cong 0.622$ is the ratio between the molar masses of water vapour and dry air. As a matter of fact, the approximation $\chi=0.622 \eta$ holds because both $\chi$ and $\eta$ are usually given and used with the precision of two significant digits ( $\chi=0.3192$ by Foken and Wichura (1996) is rather an exception).

Specific humidity is usually derived from dew point or psychrometric measurements, i.e. from the partial pressure of vapour $e$ using the approximated relation (14), but the explicit expression (Iribarne and Godson 1981) is

$$
q=\varepsilon \frac{e}{p-(1-\varepsilon) e}
$$

By substitution of Eq. 15 in Eq. 3, the expression (13) of sonic temperature as a function of vapour pressure is obtained, where

$$
\chi=\frac{\varepsilon \eta}{1-(1-\varepsilon) \frac{e}{p}}
$$

depends not only on temperature, but also on relative humidity $h$, because $e=h e_{w}(T)$, where $e_{w}(T)$ is the saturation vapour pressure.

Table 3 lists the values of $\chi$ as a function of temperature and relative humidity, calculated at $p=1013.25 \mathrm{hPa}$ using Eq. 16 with the $\eta$ values as in Table 2. Also the error $\sigma_{\chi}$ that contributes to the uncertainty of the sonic temperature as $\sigma_{T_{s}}=0.05^{\circ} \mathrm{C}$ is shown. Unlike $\eta$, whose relative uncertainty between 0 to $40{ }^{\circ} \mathrm{C}$ is equal to $0.2 \%$, $\chi$ is affected by a relative uncertainty of about $2.5 \%$, and therefore can be considered constant only with a two-digit precision. The value $\chi=0.312$, derived by applying the approximation (14) to the proposed value of $\eta$, would underestimate the $\chi$ values of Table 3 over the whole temperature range with an uncertainty contribution, in saturation conditions, $\sigma_{T_{s}}=T(e / p) \sigma_{\chi}=0.06{ }^{\circ} \mathrm{C}$ at $30{ }^{\circ} \mathrm{C}$ and $\sigma_{T_{s}}=0.2{ }^{\circ} \mathrm{C}$ at $40{ }^{\circ} \mathrm{C}$. The usual value $\chi=0.32$, on the contrary, limits the sonic temperature uncertainty below $0.05{ }^{\circ} \mathrm{C}$ at any humidity in the temperature range from -20 to $40{ }^{\circ} \mathrm{C}$, independent of the value of the relative humidity. Both the value currently used for $\chi$ in Eq. 13 and the corresponding precision appear therefore correct and satisfactory, even if Eq. 13 gives a less accurate estimate compared to Eq. 3 with $\eta=0.502$.

Being $e=h e_{w}$, Eq. 12 implies a linear dependence of the speed-of-sound squared on relative humidity. Relevant exceptions to this approximation for relative humidity below $10 \%$ have been previously predicted and confirmed by experimental determinations, as discussed in Cramer (1993), Wong and Embleton (1985b), Greenspan (1987), Trusler (1991). The humidity dependence of the speed of sound determined using Eq. 12 with $\chi=0.32$ agrees with Wong and Embleton (1985b) and Cramer (1993) theoretical predictions to within $100 \mathrm{ppm}$ in the whole range of validity of these formulations $\left(0-30{ }^{\circ} \mathrm{C}\right)$.

\section{Measurements and Method}

\subsection{Climatic chamber measurements}

The response of the anemometers to temperature and humidity was investigated at the Italian Metrological Institute (INRIM) using a temperature and relative humidity- 
controlled chamber from Weiss Technik to provide a stable and controlled environment. The chamber has a working volume of about $0.3 \mathrm{~m}^{3}\left(0.7 \times 0.7 \times 0.6 \mathrm{~m}^{3}\right)$, large enough to accommodate three anemometers. The inner walls of the chamber were covered by a $50-\mathrm{mm}$ thick layer of acoustically isolating foam. The climatic chamber operation is based on a flow-mixing design and its relative humidity working range spans from about 5 to $95 \%$ with air temperatures between $-20^{\circ} \mathrm{C}$ and $85^{\circ} \mathrm{C}$. Relative humidity and temperature conditions are continuously controlled by means of an internal psychrometer. The chamber affords a short-term relative humidity stability to within $\pm 0.5 \%$ and a temperature stability better than $0.05^{\circ} \mathrm{C}$. For accurate air and dew-point temperature measurements, two reference instruments were used. The air temperature thermometer was based on a special aspirated sensor equipped with a calibrated $100 \Omega$ platinum resistance thermometer (PRT) that was shielded from infrared radiation by means of a double-walled, gold-coated shield. The PRT resistance is read by an AC resistance bridge with a resolution of $1 \mathrm{mK}$. The estimated uncertainty of the air temperature measurement was lower than $0.1{ }^{\circ} \mathrm{C}$ at a $95 \%$ confidence level (Actis and Fernicola 1999). A small vacuum pump, connected to the aspirated thermometer, samples the air from the chamber to an external dew-point chilled-mirror hygrometer $(\mathrm{CMH})$. The $\mathrm{CMH}$ is hosted in a temperature-controlled box and is connected to the chamber through a heated hose to prevent condensation. Before starting the testing, the CMH was calibrated against the INRIM primary humidity generators (Actis et al. 1998, 1999) in the dew-point temperature range from -25 to $75^{\circ} \mathrm{C}$. The estimated calibration uncertainty was $0.08{ }^{\circ} \mathrm{C}$ at a $95 \%$ confidence level.

The three anemometers are the same previously described and used in Richiardone et al. (2008). All of them are Solent R2 models by Gill Instruments, labelled as 160 (1012R2-A model, S/N 0059), 161 (1012R2 model, S/N 0134) and 162 (1012R2 model, S/N 0144). They were simultaneously placed inside the climatic chamber, and measured the speed of sound in mode 1 (calibrated) at a $21 \mathrm{~Hz}$ sampling rate for one week, while 18 different combinations of temperature and relative humidity were selected. The data were then 5-min averaged, and only the values measured when the temperature and humidity conditions of the climatic chamber reached a stable value were considered.

The speed of sound $c^{*}$ measured by the anemometers (5-min averaged values), the reference value $c$ interpolated from the tables in Zuckerwar (2002) using $f=$ $20-50 \mathrm{kHz}$ and its approximated value $c_{a}$ calculated using Eq. 2 with $\eta=0.502$ are listed in Table 4 as a function of the temperature and humidity values measured in the climatic chamber. The atmospheric pressure was measured at ground level in the nearby meteorological station. At this same location the anemometers were deployed for accomplishing experimental work in the framework of the Urban Turbulence Project (UTP, Ferrero et al. (2009)). Wexler's relations (Wexler 1976, 1977) modified by Sonntag $(1990,1998)$ were used to calculate the saturation vapour pressure at each temperature.

The comparison between $c_{a}$ and $c$ values (Table 4 ) indicates that the approximate calculation of the speed of sound using Eq. 2 with the proposed value of $\eta$ (i.e. sonic temperature using Eq. 3) is sufficiently accurate for sonic anemometry, their relative discrepancy being less than $0.1 \%$. The experimentally determined speed of sound 
values $c^{*}$ are plotted versus the reference speed of sound $c$ in Fig. 1. In order to determine appropriate corrections to the anemometer response, a functional relationship $c=F\left(c^{*}\right)$ was conveniently derived for each anemometer by means of the following fit:

$$
F\left(c^{*}\right)=c_{0}+\frac{\sum_{i=0}^{6} a_{i}\left(c^{*}-c_{0}\right)^{i}}{\sum_{i=0}^{3} b_{i}\left(c^{*}-c_{0}\right)^{i}}
$$

with $c_{0}=340 \mathrm{~m} \mathrm{~s}^{-1}$. The inverse relationships $c^{*}=F^{-1}(c)$ are also shown in Fig. 1. By applying Eq. 1, the relationship between the measured $\left(T_{s}^{*}\right)$ and reference $\left(T_{s}\right)$ sonic temperature is then derived.

Figure 2 displays the differences between the measured and the reference sonic temperatures as a function of the reference sonic temperature. As expected, measured values agree with the curves derived by applying Eq. 1 to fit curves of Fig. 1. At both ends of the instrument operating range $\left(-20\right.$ to $\left.50{ }^{\circ} \mathrm{C}\right)$ the differences are very large, reaching a maximum value of about $9{ }^{\circ} \mathrm{C}$. Mostly, the curve slope shows large departures from the horizontal.

The slope $d T_{s}^{*} / d T_{s}$ of the sonic temperature response function $T_{s}^{*}\left(T_{s}\right)$ is obtained by adding 1 to the slope of the Fig. 2 curves. It appears that the response slope is close to 1:1 only in small ranges close to the minima and maxima of the Fig. 2 curves (around -13 and $+30{ }^{\circ} \mathrm{C}$ for the anemometer $160,-12$ and $+12{ }^{\circ} \mathrm{C}$ for the 161 and -8 and $+15^{\circ} \mathrm{C}$ for the 162). The slope of the temperature response is minimal around $-5^{\circ} \mathrm{C}$ for the anemometer 160 and 161 and around $0{ }^{\circ} \mathrm{C}$ for the 162 ; the maximal slope is reached at the upper end of the operating range. All the anemometers show positive temperature offsets, different for each instrument. These results are similar to those obtained by Loescher et al. (2005) for the Gill R3 model in the $0{ }^{\circ} \mathrm{C}-$ $30{ }^{\circ} \mathrm{C}$ temperature range. It is worth noting that a temperature offset has no influence on the measurement of temperature fluctuations, but the minimal/maximal slope of the response function at low/high temperatures implies that at low temperatures the temperature fluctuations are underestimated, whereas at high temperatures they are overestimated. This distortion directly influences the evaluation of the heat flux, as will be discussed in Sect. 4.

\subsection{Transducer delay}

The acoustic path distance is influenced by the thermal expansion of the transducer array bearings, implying a possible overestimation or an underestimation of the speed of sound as the distance reduces or increases, respectively. This effect is judged negligible across the range of tested temperatures $\left(0-30^{\circ} \mathrm{C}\right)$ by Loescher et al. (2005), and would imply an opposing behaviour at both ends of the temperature operating range, whereas Fig. 2 shows that the speed of sound is overestimated at both ends.

Another factor that may produce a relevant influence on the measurement of the speed of sound is the temperature dependency of the so-called transducer delay. The actual times measured within the instrument include the system group delay, of which the major contributors are the ultrasonic transducers. This group delay is itself a function of temperature and is determined generically from a sample batch of instruments 
and this generic correction is applied to all. This correction is termed (somewhat inaccurately) the "transducer delay curve". Figure 3 shows the typical temperature dependency of the Gill Solent R2 transducer delay according to the manufacturer (personal communication, 2011). Mortensen (1994) tested a Gill Solent R2 anemometer in a climatic chamber, observing a decrease of the delay around $3 \mu$ s between 30 and $-10^{\circ} \mathrm{C}$, causing a maximum temperature error of $5 \mathrm{~K}$.

Figure 3 shows that, typically, the delay is constant between 5 and $20^{\circ} \mathrm{C}$ but decreases as temperature departs from this interval. If the instrument software assumes a constant delay optimized around the central interval, where the measured speed of sound agrees well with the reference value, a lower delay outside the interval implies a speed overestimation, because the time-of-flight of the sound pulse is underestimated by an amount $\Delta t$ equal to the difference between the optimized and the actual delay.

In spite of being generic, the typical delay displayed in Fig. 3 may be used to determine a tentative correction of the speed-of-sound measurements in the INRIM climatic chamber by adding $\Delta t$, the time-of-flight underestimation (TOFU hereinafter), to the time-of-flight that the sound pulse is estimated to have spent to cover the sonic path length $d=150 \mathrm{~mm}$. Consequently, a delay-corrected speed of sound $c_{d}$ has been calculated as

$$
c_{d}=\frac{c^{*}}{1+\frac{c^{*}}{d} \Delta t}
$$

and is also plotted in Fig. 1, where it appears that the delay-corrected values of the speed of sound are much closer to the 1:1 slope than the raw values. This result seemingly indicates that the temperature dependency of the transducer delay is the main cause of the disagreement between the speed of sound measured by the anemometers and its theoretical value. The residual small differences between the delay-corrected values and the ideal 1:1 slope in Fig. 1 are probably due to specific differences of the transducer delay of each anemometer and to the changes in the transducer geometry due to thermal expansion.

The TOFU value $\Delta t$ is a function of the transducer temperature $T_{t}$, which in the stationary conditions of the climatic chamber coincided with the air temperature. If one assumes that in the climatic chamber the disagreement between $c^{*}$ and $c$ is entirely due to the transducer delay factor, and that the transducer temperature can be approximated by the sonic temperature, the TOFU dependence on transducer temperature can be estimated as

$$
\Delta t\left(T_{t}\right)=\frac{d}{c\left(T_{t}\right)}-\frac{d}{c^{*}\left(T_{t}\right)} .
$$

For each anemometer, the $\Delta t\left(T_{t}\right)$ curve has been derived from Eq. 19 using Eq. 1 to calculate $\mathrm{c}$ from $T_{t}$ and inverting the fit function (17) to obtain the inverse relationship $c^{*}=F^{-1}(c)$. The transducer delay dependencies on temperature (Fig. 3) have then been derived by subtracting the $\Delta t\left(T_{t}\right)$ values from the optimized, constant delay value of $32 \mu$ s estimated from the typical delay curve (continuous line of Fig. 3).

It is straightforward that at thermal equilibrium a speed-of-sound correction calculated by Eq. 18 with $\Delta t$ derived from Eq. 19 gives the same result as correcting $c^{*}$ 
using the fit curve of Fig. 1 to obtain $c$. In real conditions, however, the thermal inertia of the transducer and its exposure to solar radiation make its temperature different from the air temperature. In this case the $c^{*}$ value used in Eq. 19 and measured at temperature $T_{t}$ in thermal equilibrium conditions can be quite different from its value in Eq. 18, where it depends not only on the sonic temperature of the air but, indirectly, on the transducer temperature as well.

\subsection{Field measurements}

The calibration of the anemometers in the climatic chamber was performed immediately after the completion of the UTP experiment. In the course of this experiment the anemometers were placed outdoors on a mast and worked continuously for about 15 months. Prior to the experiment the same anemometers had been separately placed outdoors in an instrument shelter and replaced at periodic intervals through one year, in order to compare their measured sonic temperatures with reference values of the same quantity as obtained from psychrometric measurements (the shelter dimensions prevented housing more than one anemometer at a time). The shelter is painted white to minimize the influence of the sunshine on the instruments, and is mounted on a stand at about $1.5 \mathrm{~m}$ above the roof of the Physics Department building, where other meteorological instruments are deployed, including a barometer. The shelter houses a psychrometer and a hair hygrometer that measure temperature and humidity routinely (5-min averaged values). The sonic anemometer measurements were performed as in the climatic chamber (calibrated mode, $21 \mathrm{~Hz}$ sampling rate and subsequent 5-min averages), and sonic temperature derived from the anemometer measurements were compared with the theoretical values calculated from the psychrometer and barometer measurements, discarding the data obtained during fog and rainy conditions. These historical records of collected data are summarized in the plots in Fig. 4, where the curves of Fig. 2 have been added for the sake of comparison. The overall behaviour of outdoor measurements is similar to climatic chamber results, but the differences between the anemometer measurements and the theoretical values are smaller and the mean offsets between the measurements and the curves have different amounts for each anemometer. This different behaviour of the anemometers versus the measurements of the same reference psychrometer seemingly suggests that a small variation of the anemometer responses took place over the 15-27 month period separating the outdoor and climatic chamber measurements.

\section{Heat-Flux Evaluation}

In Sect. 3 it has been shown that the anemometers are characterized by a sonic temperature response $T_{s}^{*}\left(T_{S}\right)$ whose slope is close to $1: 1$ only around the centre of the temperature operating range. In the present section it will be shown that the deviations from the 1:1 slope may significantly influence the measurement of the sonic temperature fluctuations and, consequently, the heat fluxes. 
The slope of the sonic temperature response can be analyzed by calculating the derivative $d T_{s}^{*} / d T_{s}$. Taking

$$
d T_{s}=\frac{d T_{s}}{d c} \frac{d c}{d c^{*}} \frac{d c^{*}}{d T_{s}^{*}} d T_{s}^{*}
$$

using the $d T_{s} / d c=2 c /\left(\gamma_{\mathrm{d}} R_{\mathrm{d}}\right)$ relationship, the $c=F\left(c^{*}\right)$ function given by Eq. 17 and the $d c^{*} / d T_{s}^{*}=\gamma_{\mathrm{d}} R_{\mathrm{d}} /\left(2 c^{*}\right)$ relationship, Eq. 20 gives

$$
\frac{d T_{s}^{*}}{d T_{s}}=\left(\frac{d T_{s}}{d T_{s}^{*}}\right)^{-1}=\frac{c^{*}}{F}\left(\frac{d F}{d c^{*}}\right)^{-1},
$$

where the derivative is expressed as a function of $c^{*}$. By expressing $c^{*}$ as a function of $T_{s}$ using the inverse relationship $c^{*}=F^{-1}(c)$ and by means of Eq. 1, the derivative $d T_{s}^{*} / d T_{s}$ can then be calculated as a function of $T_{s}$.

A Taylor series approximation gives to first order

$$
T_{s}^{* \prime} \simeq T_{s}^{\prime}\left(\frac{d T_{s}^{*}}{d T_{s}}\right)_{T_{s}}
$$

where $T_{s}^{* \prime}$ and $T_{s}^{\prime}$ are the raw and corrected fluctuations of sonic temperature, the derivative being evaluated at the centre of the averaging time interval. The smaller are $T_{s}^{\prime}$, the averaging time interval and the truncation error in Eq. 22 (i.e. $d^{2} T_{s}^{*} / d T_{s}^{2}$ is smaller, implying a greater bending ratio of the response curve), the more accurate is the approximation. Equation 22 implies that the ratio between raw and corrected kinematic heat fluxes can be approximated as

$$
\overline{\frac{w^{\prime} T_{s}^{* \prime}}{\overline{w^{\prime} T_{s}^{\prime}}}} \simeq\left(\frac{d T_{s}^{*}}{d T_{s}}\right)_{\overline{T_{s}}}
$$

Heat fluxes are commonly measured using averaging intervals of about $30 \mathrm{~min}$ or more, so that temperature can sometimes vary in the range of several kelvins. In order to check Eq. 23 experimentally, the 15-month long series of sonic temperature measurements carried out during the UTP experiment was considered, and both raw and corrected kinematic heat fluxes have been calculated using an averaging interval of $30 \mathrm{~min}$. The corrected heat fluxes have been obtained by repeating the same calculations used for the raw fluxes, excepted that all the raw values $c^{*}$ have been previously corrected by applying Eq. 17. As has been shown in Sect. 3, this supposes that the transducer has the same temperature as the air, so neglecting its thermal inertia and any radiation effect.

The ratio between the raw and the corrected fluxes (left-hand side (1.h.s.) of Eq. 23) is plotted as a function of $\overline{T_{s}}$ in Fig. 5, allowing the comparison with the right-hand side (r.h.s.) of the same equation, evaluated by means of Eq. 21 (continuous line). To avoid large errors, only the points with an absolute value of both heat fluxes greater than $10 \mathrm{~W} \mathrm{~m}^{-2}$ have been plotted (about 7,000 points). The agreement is very good, implying that the response curve $c=F\left(c^{*}\right)$ of the anemometers is sufficiently smooth to allow the fulfilment of Eq. 23 if fluxes are evaluated with averaging intervals up to $30 \mathrm{~min}$. 
Figure 5 shows that, neglecting the correction, the kinematic heat flux is correctly evaluated only in a narrow temperature interval, with noticeable differences that depend on the instrument. In the range of low temperatures where the slope of the $T_{S}^{*}\left(T_{S}\right)$ function is lower than $1: 1$, all the anemometers underestimate the fluxes. The underestimation can reach $40 \%$. At high temperatures (and very low temperatures too) where the slope is larger than 1:1, the fluxes are overestimated, and the associate relative error can be greater than $30 \%$.

Temperature correction also influences the evaluation of the air density and, consequently, the (sensible) heat flux. From Eq. 23 and the gas law, the ratio between the raw and corrected heat fluxes results

$$
\frac{\overline{\rho^{*}} \overline{w^{\prime} T_{s}^{* \prime}}}{\bar{\rho} \overline{w^{\prime} T_{s}^{\prime}}} \simeq \frac{\overline{T_{s}}}{\overline{T_{s}^{*}}}\left(\frac{d T_{s}^{*}}{d T_{s}}\right)_{\overline{T_{s}}},
$$

where $\overline{\rho^{*}}$ and $\bar{\rho}$ are the raw and corrected mean density, respectively. The r.h.s. of Eq. 24 is also plotted as a function of $T_{S}$ in Fig. 5 (dot-dashed line), and the ratio between raw and corrected heat fluxes from the UTP experiment (not shown) agree very well with it. The density effect contributes for about $2 \%$ to the heat-flux error.

As has been shown above, the heat-flux underestimation or overestimation is due to the underestimation or overestimation of the sonic temperature fluctuations, depending on $d T_{s}^{*} / d T_{s}$ being less or greater than 1 , respectively. This occurs for sonic temperature intervals where the slope of the fit curve in Fig. 2 is negative or positive, respectively. Figure 2 shows that the point-by-point correction by means of the fit curve lowers each raw temperature by an amount that depends on the temperature itself. If the raw sonic temperature fluctuates, during a 30-min averaging interval, within a range $\Delta T_{s}^{*}$ where the slope of the curve in Fig. 2 is negative, both the positive or negative fluctuations are amplified by the correction, because a greater amount is subtracted from the lowest raw temperatures compared to the highest ones. The opposite occurs if the temperature fluctuates in a range where the slope is positive, causing a dampening of the corrected fluctuations. Therefore the corrected sonic temperature fluctuates within a range $\Delta T_{s}$ which is widened or narrowed compared with $\Delta T_{s}^{*}$ and, moreover, left-shifted by the overall temperature decrease. This behaviour is enhanced if the heat fluxes are corrected by directly applying Eq. 17 to each $c^{*}$ value, i.e. supposing that the sonic transducer has the same temperature as the air. Actually, a correction based on the transducer temperature smooths the result, because the amount of the temperature subtraction is evaluated at temperatures that fluctuate much less than the air temperature, due to transducer th0ermal inertia.

In order to evaluate the influence of thermal inertia on the heat-flux calculation, the vector of the raw values of the speed of sound $c^{*}$ collected during the 30-min averaging interval is processed by means of an iterative procedure that operates on the vectors of the corrected speed of sound $c$ and the corrected sonic temperature of the air $T_{s}$. The $c$ vector is set to its initial state $c^{(0)}$ by means of Eq. 17 applied to $c^{*}$ elements, then $T_{s}$ is initialized to $T_{s}^{(0)}$ state by applying Eq. 1 to each element of $c^{(0)}$. At every iteration $k$, each $i$ th-element $c^{(k)}(i)$ of vector $c^{(k)}$ is updated from the raw value $c^{*}(i)$ using Eq. 18, where the TOFU value $\Delta t^{(k)}(i)$ is derived by means of Eq. 19 from an estimate of the transducer temperature $T_{t}^{(k-1)}(i)$ at the same $i t 0 \mathrm{~h}$ 
instant during the previous iteration step. The transducer temperature $T_{t}^{(k-1)}(i)$ is estimated as the mean of the values of the air temperature $T_{s}^{(k-1)}$ that occur during a time interval $\bar{t}$ preceding the $i$ th instant. The $T_{s}$ vector is then updated to $T_{s}^{(k)}$ state by applying Eq. 1 to $c^{(k)}$, and so on. The procedure is stopped (usually after 5-10 iterations) when the mean square difference between the $T_{S}$ elements of the last two iterations is lower than $0.001{ }^{\circ} \mathrm{C}$. The ratios between the raw values of the kinematic heat fluxes and those corrected by applying this procedure are compared in Fig. 5 with the "instantaneous correction" (i.e. using $\bar{t}=0$ ) results obtained by neglecting the thermal inertia of the transducer. They are much more scattered, and therefore their values have been sub-divided in $2{ }^{\circ} \mathrm{C}$-wide bins (the mean values of each bin are connected by the coloured lines; only the standard deviations at alternating bins are shown for greater clarity). There is not much difference between the results obtained using $\bar{t}=30 \mathrm{~s}$ or $\bar{t}=60 \mathrm{~s}$, whereas using $\bar{t}=10 \mathrm{~s}$ the results are much closer to those of the "instantaneous correction". As expected, it appears that thermal inertia reduces, on the mean, the heat-flux underestimation below $25 \%$ and the overestimation below $10 \%$. Nevertheless, the standard deviation values of the underestimation can reach $15 \%$, implying that the heat flux can sometimes be underestimated by up to $40 \%$, i.e. of the same amount obtained by applying to each raw value of the speed of sound the "instantaneous correction" given by the fit curve of Eq. 17. Figure 5 shows that the standard deviation $\sigma_{k}$ of the kinematic heat-flux ratio is greater where the continuous black curve is farther from the ordinate 1.0, suggesting some dependence on $x=A B S\left(d T_{s}^{*} / d T_{s}-1\right)$. In the case $\bar{t}=60 \mathrm{~s}$ the plots of $\sigma_{k}$ versus $x$ (not shown) indicate a linear dependence $\sigma_{k}=a x$ for all the anemometers, with the coefficient $a$ equal to $0.32,0.36,0.32$ and the square of the linear correlation coefficient $r^{2}$ equal to $0.97,0.93,0.85$ for the anemometers 160,161 and 162 , respectively. A similar linear relationship, $m_{k}=b x$, holds for the mean value $m_{k}$ of the kinematic flux ratio $\overline{w^{\prime} T_{s}^{* \prime}} / \overline{w^{\prime} T_{s}^{\prime}}$ (blue curve in Fig. 5), with the coefficient $b$ equal to $0.53,0.61,0.63$ and $r^{2}$ equal to $0.95,0.97,0.95$ for the anemometers 160,161 and 162 , respectively.

In conclusion, the thermal inertia of the sonic transducers is an important factor that influences the measurements of sonic temperature fluctuations. Turbulent heat fluxes, as well as the other turbulent variables involving the temperature, are thus affected. The iterative procedure that has been described can be useful tool to correct the measurements, provided that the response curve of each anemometer has been determined in a climatic chamber. An estimate of the thermal inertia is necessary, but this does not prevent additional heating of the transducers caused by solar radiation influencing the measurements in an unpredictable way. The transducer delay issue can therefore be entirely settled only if the transducer temperature is expressly measured.

\section{Conclusions}

A rigorous evaluation of the speed of sound in moist air confirmed the validity of the coefficients commonly used to account for the linear dependence of sonic temperature on the partial pressure of water vapour and on specific humidity, yet suggesting the adoption of a more accurate value for the latter. 
Extensive measurements in a climatic chamber and in the field using Solent R2 sonic anemometers manufactured by Gill Instruments showed that the slope of the sonic temperature response is close to $1: 1$ only in a narrow temperature interval, typically at the centre of the operating range, depending on the instrument. It has been proved that the departure from the 1:1 slope, a feature that affects many sonic anemometer models, influences not only the measurement of the sonic temperature of the air, but also the evaluation of its fluctuations, and hence the heat flux and all the turbulent variables involving the temperature.

With regard to Solent R2 anemometers, the heat fluxes were found to be underestimated in the lower part of the operating range and overestimated in the upper. The error is mainly due to the temperature dependence of the so-called transducer delay, which influences the measurement of the speed of sound. In order to obtain accurate measurements of the heat flux it is therefore necessary that the temperature response of each instrument is determined by calibration in a climatic chamber and that corrections are then applied to sonic data. In the open air, however, the transducer temperature fluctuates much less than the temperature of the air. It has been shown that, if the thermal inertia of the sonic transducers is known, even roughly, it is possible to estimate the transducer temperature and therefore correct the measurements, provided that the transducer heating caused by solar radiation is negligible. Thermal inertia reduces, on average, the heat-flux underestimation below $25 \%$ and the overestimation below $10 \%$, but the standard deviation of the underestimation can reach $15 \%$, implying that the heat flux can sometimes be underestimated by up to $40 \%$.

In conclusion, it must be pointed out that the temperature response may be subject to variations in the long run and that the transducer delay issue can be entirely settled only if the transducer temperature is measured, because the radiative heating of the transducers cannot be estimated. Due to the significance of the heat-flux measurements it is therefore advisable that calibration procedures are routinely adopted, the thermal inertia of sonic transducers estimated or, better, their temperature expressly measured.

Acknowledgements We thank the anonymous reviewers for their suggestions, and in particular for having focused the attention on the transducer delay effect. The help of Niels Mortensen (Risø National Laboratory) and Murree Sims (Gill Instruments Ltd.) is gratefully acknowledged.

\section{References}

Actis, A. and Fernicola, V. C. (1999). A reference instrument for accurate measurements of air temperature. In Proc. $15^{\text {th }}$ World Congress of the International Measurement Confederation (IMEKO XV), Osaka, Japan, volume 7, pages 191-196.

Actis, A., Banfo, M., Fernicola, V. C., Galleano, R., and Merlo, S. (1998). Metrological performances of the IMGC two-temperature primary humidity generator for the temperature range $-15^{\circ} \mathrm{C}$ to $90{ }^{\circ} \mathrm{C}$. In Proc. $3^{\text {rd }}$ International Symposium on Humidity and Moisture, Teddington, UK, volume 1, pages 2-9.

Actis, A., Fernicola, V. C., and Banfo, M. (1999). Characterisation of the IMGC frost point generator in the temperature range $-75^{\circ} \mathrm{C}$ to $0{ }^{\circ} \mathrm{C}$. In Proc. Tempmeko '99, Delft, The Netherlands, volume 1 , pages $185-190$.

Barrett, E. W. and Suomi, V. E. (1949). Preliminary report on temperature measurement by sonic means. J. Meteorol., 6, 273-276. 
Cramer, O. (1993). The variation of the specific heat ratio and the speed of sound in air with temperature, pressure, humidity and $\mathrm{CO}_{2}$ concentration. J. Acoust. Soc. Am., 93, 2510-2516.

Ferrero, E., Anfossi, D., Richiardone, R., Trini Castelli, S., Mortarini, L., Carretto, E., Muraro, M., Bande, S., and Bertoni, D. (2009). Urban turbulence project. The field experimental campaign. Internal Report ISAC-TO/02-2009, pages 1-37.

Foken, T. and Wichura, B. (1996). Tools for quality assessment of surface-based flux measurements. Agric. For. Meteorol., 78, 83-105.

Greenspan, M. (1987). Comments on 'Speed of sound in standard air' [J. Acoust. Soc. Am., 79, 1359-1366 (1986)]. J. Acoust. Soc. Am., 82, 370-372.

Hignett, P. (1992). Corrections to temperature measurements with a sonic anemometer. Boundary-Layer Meteorol., 61, 175-187.

Högstrom, U. and Smedman, A. (2004). Accuracy of sonic anemometers: laminar wind-tunnel calibrations compared to atmospheric in situ calibrations against a reference instrument. Boundary-Layer Meteorol., 111, 33-54.

Iribarne, J. V. and Godson, W. L. (1981). Atmospheric Thermodynamics. Geophys. Astrophys. Monogr., Reidel, Dordrecht.

Ishii, C. (1935). Supersonic velocity in gases. Sci. Pap. Inst. Phys. Chem. Res. Tokyo, 26, 201-207.

ISO (1975). Standard Atmosphere. ISO 2533-1975, Geneva.

Kaimal, J. C. and Businger, J. A. (1963). A continuous-wave sonic anemometer-thermometer. J. Appl. Meteorol., 2, 156-164.

Kaimal, J. C. and Gaynor, J. E. (1991). Another look at sonic thermometry. Boundary-Layer Meteorol., 56, 401-410.

Lemmon, E. W., Jacobsen, R. T., Penoncello, S. G., and Friend, D. G. (2000). Thermodynamic properties of air and mixtures of nitrogen, argon, and oxygen from 60 to $2000 \mathrm{~K}$ at pressures to $2000 \mathrm{MPa}$. J. Phys. Chem. Ref. Data, 29, 331-385.

Liu, H., Peters, G., and Foken, T. (2001). New equations for sonic temperature variance and buoyancy heat flux with an omnidirectional sonic anemometer. Boundary-Layer Meteorol., 100, 459-468.

Loescher, H. W., Ocheltree, T., Tanner, B., Swiatek, E., Dano, B., Wong, J., Zimmerman, G., Campbell, J., Stock, C., Jacobsen, L., Shiga, Y., Kollas, J., Liburdy, J., and Law, B. E. (2005). Comparison of temperature and wind statistics in contrasting environments among different sonic anemometerthermometers. Agric. For. Meteorol., 133, 119-139.

Mortensen, N. G. (1994). Wind measurements for wind energy applications - a review. In Wind Energy Conversion. Proc. of the $16^{\text {th }}$ British Wind Energy Association Conference, Stirling, Scotland, 15-17 June 1994, pages 353-360.

Richiardone, R., Giampiccolo, E., Ferrarese, S., and Manfrin, M. (2008). Detection of flow distortions and systematic errors in sonic anemometry using the planar fit method. Boundary-Layer Meteorol., 128, 277-302.

Schotanus, P., Nieuwstadt, F. T. M., and De Bruin, H. A. R. (1983). Temperature measurement with a sonic anemometer and its application to heat and moisture fluxes. Boundary-Layer Meteorol., 26, 81-93.

Sonntag, D. (1990). Important new values of the physical constants of 1986, vapour pressure formulations based on the ITS-90, and psychrometer formulae. Z. Meteorol., 70, 340-344.

Sonntag, D. (1998). The history of formulations and measurements of saturation water vapour pressure. In Proc. $3^{\text {rd }}$ Internationall Symposyum on Humidity and Moisture, Teddington, UK, volume 1, pages 93-102.

Trusler, J. P. M. (1991). Physical acoustics and metrology of fluids. Adam Hilger, Bristol.

Wagner, W. and Pruss, A. (2002). The IAPWS formulation 1995 for the thermodynamic properties of ordinary water substance for general and scientific use. J. Phys. Chem. Ref. Data, 31, 387-535.

Wexler, A. (1976). Vapor pressure formulation for water in range 0 to $100{ }^{\circ}$ C. a revision. J. Res. Natl. Bur. Stand., 80A, 775-785.

Wexler, A. (1977). Vapor pressure formulation for ice. J. Res. Natl. Bur. Stand., 81A, 5-20.

Wong, G. S. K. and Embleton, F. W. (1985a). Experimental determination of the variation of specific heat ratio in air with humidity. J. Acoust. Soc. Am., 77, 402-407.

Wong, G. S. K. and Embleton, F. W. (1985b). Variation of the speed of sound in air with humidity and temperature. J. Acoust. Soc. Am., 77, 1710-1711.

Zuckerwar, A. J. (2002). Handbook of speed of sound in real gases vol III - Speed of sound in Air. Academic Press, Amsterdam. 
Table 1 Specific-heat capacities and their ratio at different temperatures and $p=1013.25 \mathrm{hPa}$ for dry air and water vapour on the vapour-liquid phase boundary, interpolated from Tables in Lemmon et al. (2000) and Wagner and Pruss (2002)

\begin{tabular}{|c|c|c|c|c|c|c|}
\hline \multirow[t]{2}{*}{$T\left({ }^{\circ} \mathrm{C}\right)$} & \multicolumn{3}{|c|}{ Dry air } & \multicolumn{3}{|c|}{ Water vapour } \\
\hline & $\begin{array}{c}c_{p_{\mathrm{d}}} \\
\left(\mathrm{J} \mathrm{kg}^{-1} \mathrm{~K}^{-1}\right)\end{array}$ & $\begin{array}{c}c_{v \mathrm{~d}} \\
\left(\mathrm{~J} \mathrm{~kg}^{-1} \mathrm{~K}^{-1}\right)\end{array}$ & $\gamma_{\mathrm{d}}$ & $\begin{array}{c}c_{p_{\mathrm{v}}} \\
\left(\mathrm{J} \mathrm{kg}^{-1} \mathrm{~K}^{-1}\right)\end{array}$ & $\begin{array}{c}c_{v \mathrm{v}} \\
\left(\mathrm{J} \mathrm{kg}^{-1} \mathrm{~K}^{-1}\right)\end{array}$ & $\gamma_{\mathrm{v}}$ \\
\hline$*$ & 1004.7 & 717.6 & 1.400 & 1846.1 & 1384.6 & 1.333 \\
\hline-20 & 1005.9 & 716.6 & 1.404 & 1860.2 & 1398.7 & 1.330 \\
\hline-10 & 1005.9 & 716.9 & 1.403 & 1864.0 & 1402.5 & 1.329 \\
\hline 0 & 1005.9 & 717.0 & 1.403 & 1884.4 & 1418.4 & 1.329 \\
\hline 10 & 1006.0 & 717.3 & 1.402 & 1894.7 & 1426.9 & 1.328 \\
\hline 20 & 1006.4 & 717.8 & 1.402 & 1905.9 & 1435.9 & 1.327 \\
\hline 30 & 1006.7 & 718.4 & 1.401 & 1918.0 & 1445.2 & 1.327 \\
\hline 40 & 1007.2 & 718.8 & 1.401 & 1931.4 & 1455.2 & 1.331 \\
\hline 50 & 1007.9 & 719.5 & 1.401 & 1946.8 & 1466.3 & 1.328 \\
\hline
\end{tabular}

Water vapour values below $0{ }^{\circ} \mathrm{C}$ have been interpolated from Table IV-5 of Iribarne and Godson (1981), using $c_{v \mathrm{v}}=c_{p_{\mathrm{v}}}-R_{\mathrm{v}}$. Asterisks indicate predicted values from ideal gas kinetic theory

Table 2 Temperature dependence (at $p=1013.25 \mathrm{hPa}$ ) of the parameters defined in Sect. 2

\begin{tabular}{ccccc}
\hline$T\left({ }^{\circ} C\right)$ & $\alpha$ & $\beta$ & $v$ & $\eta$ \\
\hline$*$ & 0.837 & 0.929 & 0.092 & 0.516 \\
-20 & 0.849 & 0.952 & 0.103 & 0.505 \\
-10 & 0.853 & 0.956 & 0.103 & 0.505 \\
0 & 0.873 & 0.978 & 0.105 & 0.503 \\
10 & 0.883 & 0.989 & 0.106 & 0.502 \\
20 & 0.894 & 1.000 & 0.106 & 0.502 \\
30 & 0.905 & 1.012 & 0.107 & 0.501 \\
40 & 0.918 & 1.024 & 0.106 & 0.502 \\
50 & 0.932 & 1.038 & 0.106 & 0.502 \\
\hline
\end{tabular}

Asterisks indicate predicted values from ideal gas kinetic theory 
Table 3 Coefficient $\chi$ as a function of temperature $T$ and relative humidity $h$ at $p=1013.25 \mathrm{hPa}$

\begin{tabular}{|c|c|c|c|c|c|c|}
\hline \multirow[t]{2}{*}{$T\left({ }^{\circ} \mathrm{C}\right)$} & \multirow[t]{2}{*}{$e_{w}(\mathrm{hPa})$} & \multicolumn{5}{|c|}{$h$} \\
\hline & & 0.2 & 0.4 & 0.6 & 0.8 & 1.0 \\
\hline-20 & 1.2559 & $\begin{array}{c}0.314 \\
(0.797)\end{array}$ & $\begin{array}{c}0.314 \\
(0.398)\end{array}$ & $\begin{array}{c}0.314 \\
(0.266)\end{array}$ & $\begin{array}{c}0.314 \\
(0.199)\end{array}$ & $\begin{array}{c}0.314 \\
(0.159)\end{array}$ \\
\hline-10 & 2.8652 & $\begin{array}{c}0.314 \\
(0.336)\end{array}$ & $\begin{array}{c}0.314 \\
(0.168)\end{array}$ & $\begin{array}{c}0.314 \\
(0.112)\end{array}$ & $\begin{array}{c}0.314 \\
(0.084)\end{array}$ & $\begin{array}{c}0.314 \\
(0.067)\end{array}$ \\
\hline 0 & 6.11213 & $\begin{array}{c}0.313 \\
(0.152)\end{array}$ & $\begin{array}{c}0.313 \\
(0.076)\end{array}$ & $\begin{array}{c}0.313 \\
(0.051)\end{array}$ & $\begin{array}{c}0.313 \\
(0.038)\end{array}$ & $\begin{array}{c}0.314 \\
(0.030)\end{array}$ \\
\hline 10 & 12.2813 & $\begin{array}{c}0.313 \\
(0.073)\end{array}$ & $\begin{array}{c}0.313 \\
(0.036)\end{array}$ & $\begin{array}{c}0.313 \\
(0.024)\end{array}$ & $\begin{array}{c}0.313 \\
(0.018)\end{array}$ & $\begin{array}{c}0.314 \\
(0.015)\end{array}$ \\
\hline 20 & 23.3925 & $\begin{array}{c}0.313 \\
(0.037)\end{array}$ & $\begin{array}{c}0.313 \\
(0.018)\end{array}$ & $\begin{array}{c}0.314 \\
(0.012)\end{array}$ & $\begin{array}{c}0.314 \\
(0.009)\end{array}$ & $\begin{array}{c}0.315 \\
(0.007)\end{array}$ \\
\hline 30 & 42.4703 & $\begin{array}{c}0.313 \\
(0.020)\end{array}$ & $\begin{array}{c}0.314 \\
(0.010)\end{array}$ & $\begin{array}{c}0.315 \\
(0.007)\end{array}$ & $\begin{array}{c}0.316 \\
(0.005)\end{array}$ & $\begin{array}{c}0.317 \\
(0.004)\end{array}$ \\
\hline 40 & 73.8530 & $\begin{array}{c}0.314 \\
(0.011)\end{array}$ & $\begin{array}{c}0.316 \\
(0.005)\end{array}$ & $\begin{array}{c}0.317 \\
(0.004)\end{array}$ & $\begin{array}{c}0.319 \\
(0.003)\end{array}$ & $\begin{array}{c}0.321 \\
(0.002)\end{array}$ \\
\hline 50 & 123.5274 & $\begin{array}{c}0.315 \\
(0.006)\end{array}$ & $\begin{array}{c}0.318 \\
(0.003)\end{array}$ & $\begin{array}{c}0.321 \\
(0.002)\end{array}$ & $\begin{array}{c}0.324 \\
(0.002)\end{array}$ & $\begin{array}{c}0.327 \\
(0.001)\end{array}$ \\
\hline
\end{tabular}

Values in brackets indicate the error $\sigma_{\chi}$ that contributes as $\sigma_{T_{s}}=0.05{ }^{\circ} \mathrm{C}$ to the uncertainty of the sonic temperature; $e_{w}$ is the saturation vapour pressure (over pure liquid water, from Sonntag (1990))

Table 4 Reference speed of sound $c$ calculated using Eq. 6, its approximated value $c_{a}$ calculated using Eq. 2 with $\eta=0.502$ and $\gamma_{\mathrm{d}}$ from Table 1 , and speed of sound $c^{*}$ measured by each anemometer in different conditions of temperature $(T)$, relative humidity $(h)$ and pressure $(p)$

\begin{tabular}{|c|c|c|c|c|c|c|c|c|c|}
\hline \multirow[t]{2}{*}{ Set point } & \multirow[t]{2}{*}{$T\left({ }^{\circ} \mathrm{C}\right)$} & \multirow[t]{2}{*}{$h(\%)$} & \multirow[t]{2}{*}{$e(\mathrm{~Pa})$} & \multirow[t]{2}{*}{$p(\mathrm{hPa})$} & \multirow[t]{2}{*}{$c_{a}\left(\mathrm{~ms}^{-1}\right)$} & \multirow[t]{2}{*}{$c\left(\mathrm{~m} \mathrm{~s}^{-1}\right)$} & \multicolumn{3}{|c|}{$c^{*}\left(\mathrm{~m} \mathrm{~s}^{-1}\right)$} \\
\hline & & & & & & & 160 & 161 & 162 \\
\hline 1 & -20.16 & 70.8 & 72.0 & 991 & 319.4 & 319.1 & 324.1 & 323.2 & 321.4 \\
\hline 2 & -15.06 & 72.9 & 119.7 & 989 & 322.5 & 322.2 & 327.8 & 326.9 & 325.3 \\
\hline 3 & -15.70 & 72.6 & 112.5 & 990 & 322.1 & 321.8 & 327.5 & 326.7 & - \\
\hline 4 & -10.23 & 76.5 & 194.9 & 992 & 325.5 & 325.2 & 330.5 & 330.3 & 329.2 \\
\hline 5 & -5.28 & 79.0 & 310.0 & 988 & 328.6 & 328.3 & 332.5 & 332.4 & 332.5 \\
\hline 6 & -0.29 & 82.5 & 492 & 991 & 331.8 & 331.4 & 334.4 & 334.1 & 334.4 \\
\hline 7 & 4.44 & 51.0 & 428 & 988 & 334.5 & 334.3 & 336.8 & 336.3 & 336.0 \\
\hline 8 & 4.45 & 39.9 & 335 & 987 & 334.5 & 334.3 & 336.8 & 336.3 & 336.0 \\
\hline 9 & 9.44 & 28.3 & 335 & 990 & 337.4 & 337.3 & 339.5 & 339.0 & 338.1 \\
\hline 10 & 19.26 & 15.0 & 335 & 989 & 343.2 & 343.0 & 344.9 & 344.9 & 343.6 \\
\hline 11 & 29.02 & 24.8 & 995 & 988 & 349.2 & 349.0 & 350.7 & 351.6 & 350.8 \\
\hline 12 & 29.03 & 36.6 & 1469 & 981 & 349.4 & 349.3 & 351.1 & 351.9 & 351.1 \\
\hline 13 & 32.93 & 20.4 & 1023 & 987 & 351.4 & 351.3 & 352.9 & 354.3 & 353.8 \\
\hline 14 & 36.82 & 18.8 & 1172 & 986 & 353.7 & 353.6 & 355.3 & 356.9 & 356.6 \\
\hline 15 & 40.78 & 18.5 & 1421 & 989 & 356.1 & 356.0 & 358.3 & 360.1 & 359.7 \\
\hline 16 & 44.69 & 17.6 & 1662 & 989 & 358.5 & 358.4 & 361.2 & 362.9 & 362.3 \\
\hline 17 & 48.58 & 19.0 & 2184 & 989 & 361.0 & 361.0 & 364.4 & 366.1 & 365.4 \\
\hline 18 & 48.53 & 43.9 & 5036 & 988 & 362.6 & 362.5 & 366.3 & 367.9 & 367.0 \\
\hline
\end{tabular}

Vapour pressure $(e)$ is also shown. Relative humidity of the first six points is calculated over ice 

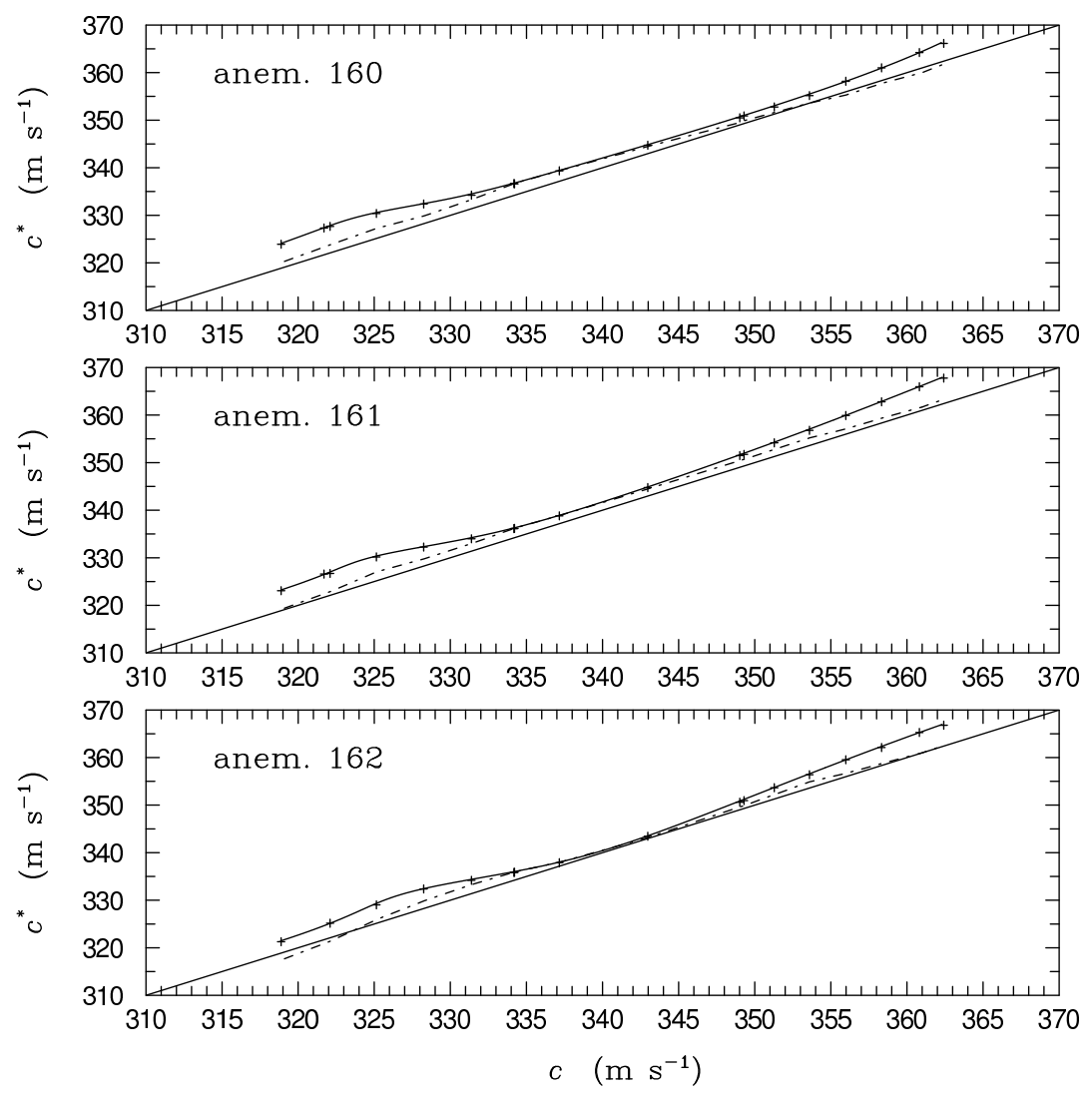

Fig. 1 Speed of sound $c^{*}$ measured by each anemometer in the climatic chamber versus the reference value $c$ (crosses). The response curves estimated by the fit are also plotted (continuous lines). Dot-dashed segments connect the delay-corrected speed of sound measurements $c_{d}$, from Eq. 18 applied to the typical transducer delay curve shown in Fig. 3 . Straight line represents 1:1 

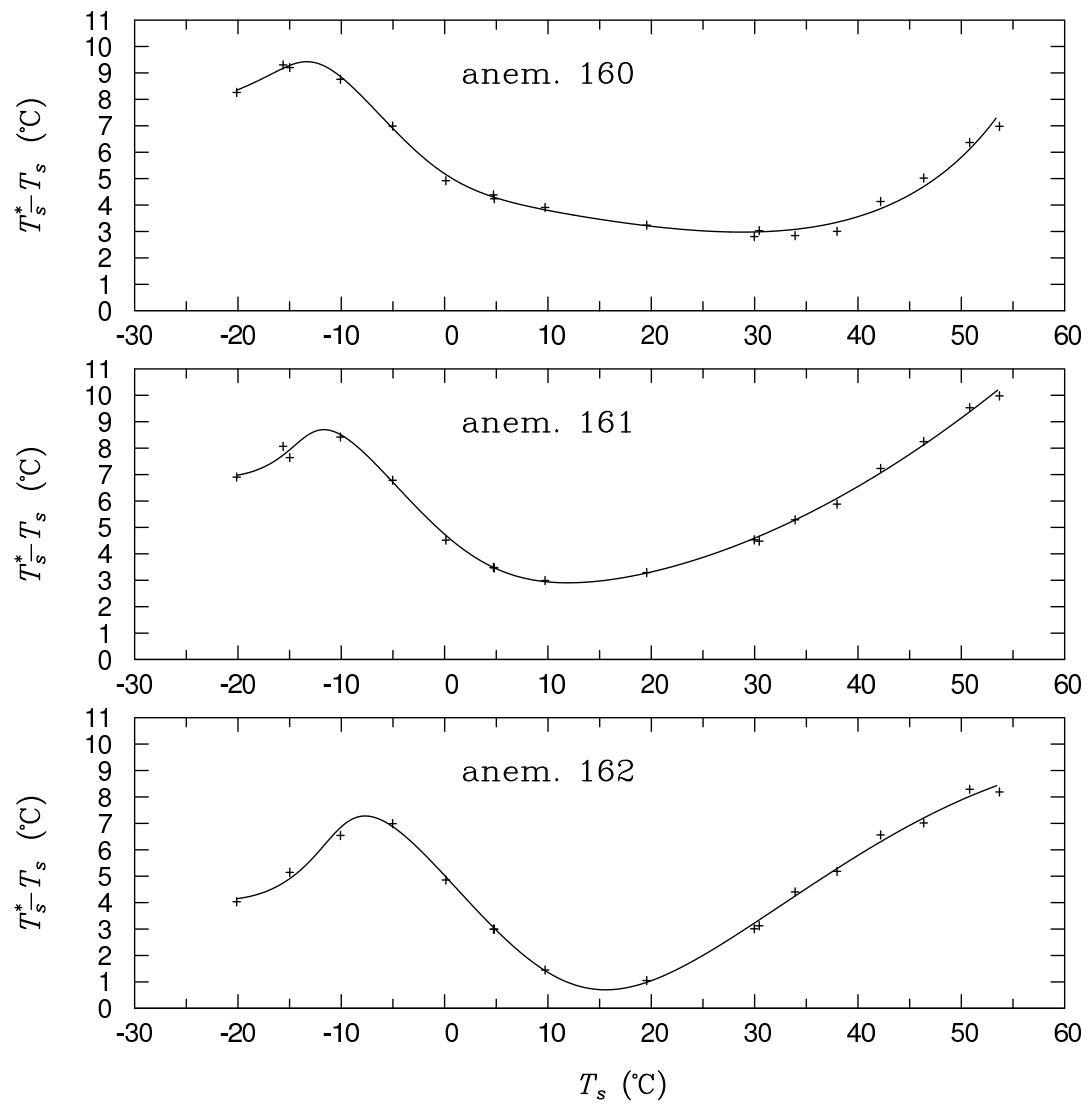

Fig. 2 Difference between sonic temperature $T_{s}^{*}$ measured by each anemometer in the climatic chamber and the reference value $T_{s}$ versus $T_{s}$ (crosses). The curves are derived by applying Eq. 1 to fit curves of Fig. 1 


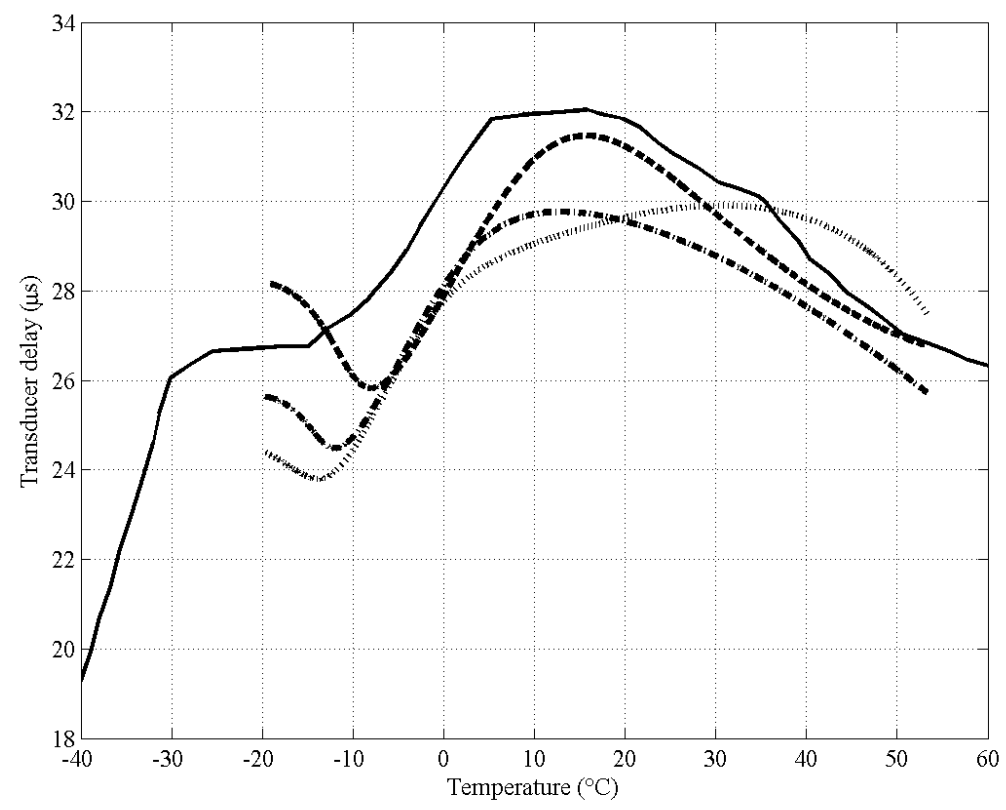

Fig. 3 Typical temperature dependency of a Gill Solent R2 transducer delay according to the manufacturer (continuous line) and specific values estimated from the climatic chamber measurements for anemometer 160 (dotted line), 161 (dash-dotted line) and 162 (dashed line) 

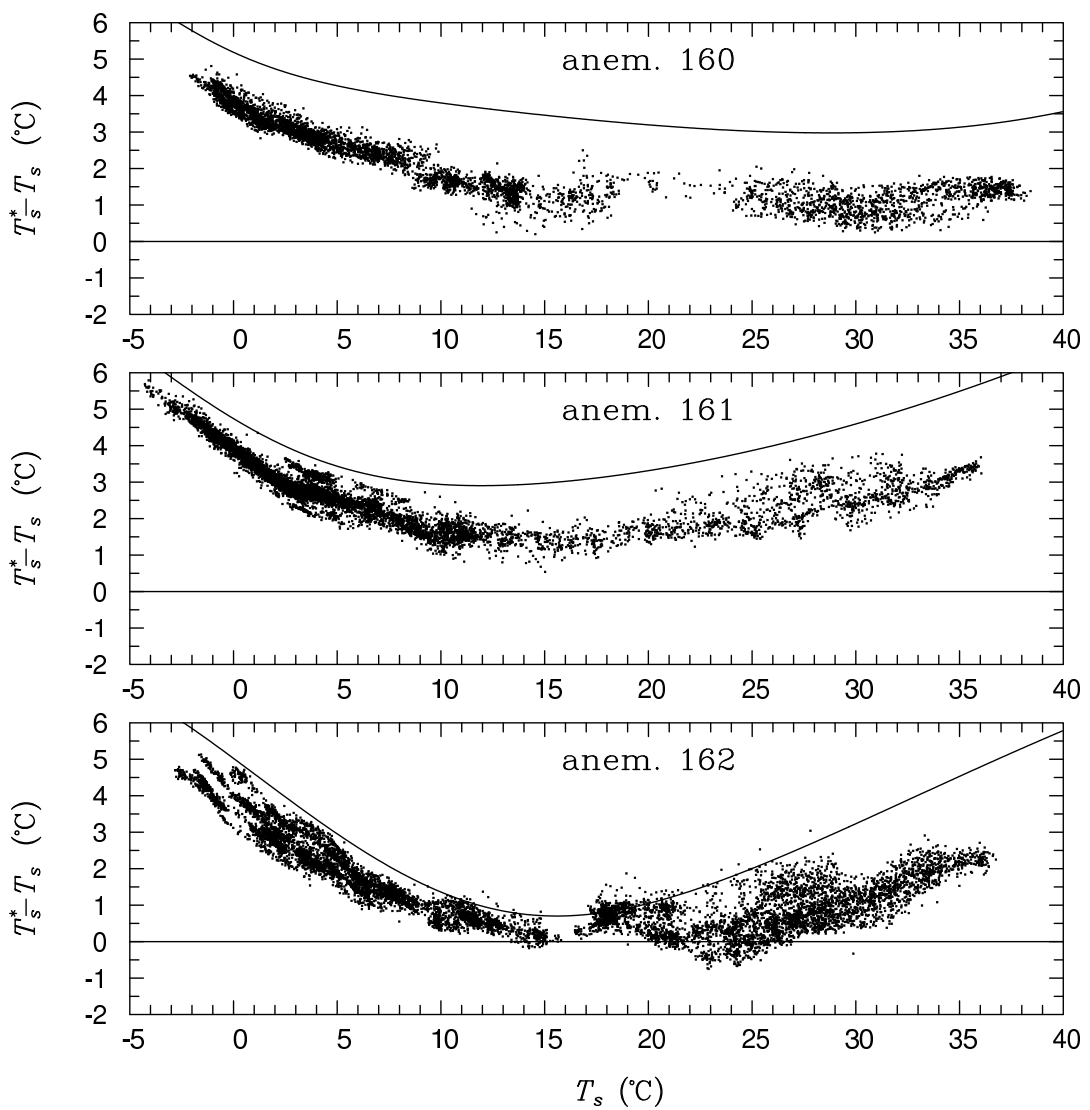

Fig. 4 Difference between the sonic temperature $T_{s}^{*}$ measured outdoors by each anemometer versus the reference value $T_{s}$, and curves from the calibration in the climatic chamber 

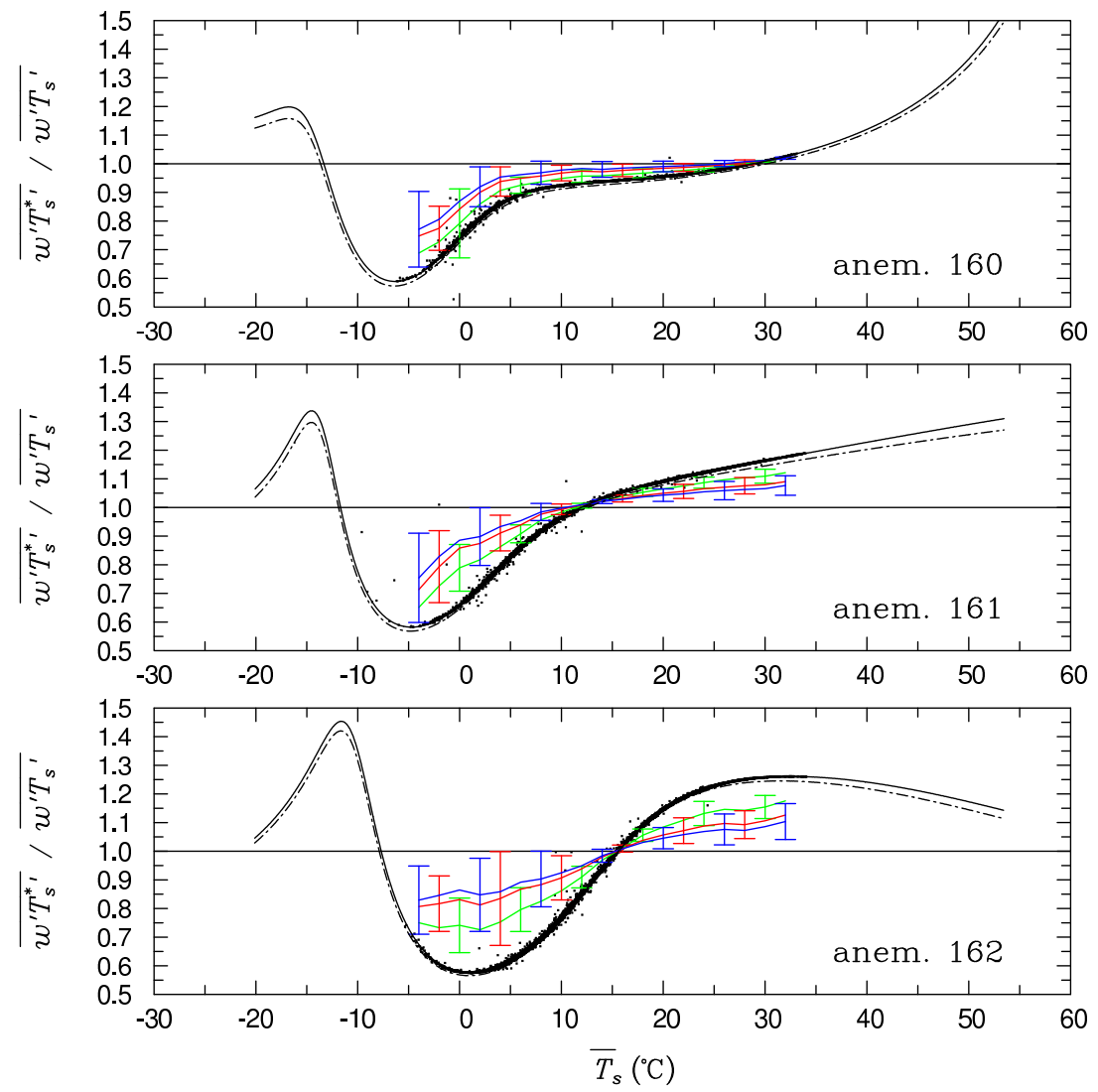

Fig. 5 Ratio between raw and corrected kinematic heat fluxes in the UTP experiment as a function of the mean value of the corrected sonic temperature. The heat fluxes have been corrected by neglecting the thermal inertia of the sonic transducers (dot points) or estimating that the transducer temperature is equal to the 10-s (green curve), 30-s (red curve) or 60-s (blue curve) mean of the air temperature. The continuous and the dot-dashed black curves indicate the r.h.s of Eq. 23 and Eq. 24, respectively 